\title{
Application of Peer Instruction in General Physics Experiment Course
}

\author{
Cheng $\mathrm{Hu}^{1}$, a, Yanjun Gao1,b and Xianming Liu 1, $\mathrm{c}^{*}$ \\ ${ }^{1}$ School of Sciences, Hubei University for Nationalities, Enshi, Hubei 445000, China \\ aenshihucheng@163.com, bgaoyjjwc@sina.com, 'liuxianming1980@163.com
}

Keywords: Peer instruction; General physics experiment course; Logical thinking; Physical literacy

\begin{abstract}
With the social progress and development in China, market competition becomes increasingly fierce. In order to seek more long-term development, China has proposed higher requirements over the cause of education, which takes the training of comprehensive talents as the main objective and transmits more talents to promote social development. On this basis, it is an inevitable choice to apply a new teaching method in the general physics experiment course. As an innovative teaching method, peer instruction, in the practical application, can effectively stimulate students' interests in studies, get them actively involved, develop good experimental creation ability and physical literacy, train their logical thinking capacity, and have a far-reaching impact on the comprehensive development of students' overall quality. As a result, this paper mainly analyzes the application of peer instruction in the general physics experiment course, combines with the actual situation, and objectively describes its key application points and roles, in order to better enhance the teaching effects of the physics experiment course.

In the traditional teaching, teacher is the main body of classroom, there is little interaction between teachers and students, students often do not dare to express their opinions, and teachers attach little importance to questions asked by students, which seriously inhibit students' learning efficiency. Such teaching conditions make it hard to doubt teachers. Nevertheless, in Western countries, this cramming teaching method has been replaced as early as the end of last century. They adopt new teaching methods, focus on the cultivation of students' self-learning ability and overall quality, encourage students to actively participate in learning and dare to doubt teachers, and carry out teaching discussions. After comparing with the current educational conditions between China and the US, relevant scholars have found that Chinese students study very hard, have very solid basic skills, and they are good at coping with all kinds of tests, yet they show poor practical abilities, inadequate flexibility, and do badly in asking questions and solving problems. In the teaching of physics experiment, Chinese students show defects in practical ability and innovation ability. The training of practical ability and innovation ability for college students has become a priority for the current teaching reform of the physics experiment course.
\end{abstract}

\section{Introduction to Peer Instruction}

Peer instruction was proposed by professor of Harvard University Eric Mazur. It is a new teaching method based on cooperative learning theory. Compared to traditional teaching, peer instruction pay more attention to cultivating students' overall quality, exercising students' self-inquiry learning ability before class and completing the study plan before class. According to the effects of preview before class, teachers classify courses into different stages to carry out teaching activities, design the tests in a targeted manner by combining with each knowledge point, and thus inspect the students' learning outcomes ${ }^{[1]}$. With the interactive feedback system, teachers are able to timely and effectively know about the learning effects of students, eventually determine the course schedule and how to organize the implementation of teaching activities, and then cultivate students' physical literacy. Peer instruction starts earlier in developed educational countries, and it is later introduced to China. However, owing to insufficient theoretical basis and practice, it has not been popularized and promoted on a national scale. Through continuous improvements and innovations, its application in 
practical teaching activities has achieved substantial results, and it has gradually become a teaching mode more suitable for the national conditions in China.

Table 1 Arrangement for General Physics Experiment

\begin{tabular}{|c|c|c|c|c|c|c|}
\hline Stu & Exp1 & Exp2 & Exp3 & Exp4 & Exp 5 & Exp 6 \\
\hline $1-9$ & First Time & Second Time & Third Time & Fourth Time & Fifth Time & Sixth Time \\
\hline $10-18$ & Sixth Time & First Time & Second Time & Third Time & Fourth Time & Fifth Time \\
\hline $19-27$ & Fifth Time & Sixth Time & First Time & Second Time & Third Time & Fourth Time \\
\hline $28-36$ & Fourth Time & Fifth Time & Sixth Time & First Time & Second Time & Third Time \\
\hline $37-45$ & Third Time & Fourth Time & Fifth Time & Sixth Time & First ime & Second Time \\
\hline $46-54$ & Second Time & Third Time & Fourth Time & Fifth Time & Sixth Time & First Time \\
\hline
\end{tabular}

Above all, peer instruction can be seen as an assisted instruction system. Lots of teaching practices have proved that it can effectively improve the effects of classroom teaching under the conditions of inadequate time and money, so it is a viable method[2].

\section{Application Conditions for Peer Instruction}

Because of the characteristics of general physics experiment, it is difficult to have adequate financial supports to carry out experiments. In addition, owing to expensive experiment devices and limited quantity, only 5 to 10 sets of experiment devices can be used in each experiment project, so most general physics experiment course can only adopt the cycled experiment method. For example, there are 54 students in a class, 6 physics experiments are designed by the teaching syllabus, so teachers will often adopt the cycled method to arrange the physics experiments. They will divide students into 6 groups, and each group has 9 students, as shown in Table 1.

From Table 1, the number of students corresponding to different times is 9 with 5 sets of devices, each group has two students, and thus a class teaching and learning environment is established. In the teaching activities of general physics experiment course, first students need to know about the experiment goal, principle, operating procedures and precautions; teachers should provide universal education for students, and train students to form the habit of taking real-time notes. The group members shall appoint a student to explain the experiment. In the subsequent implementation of the teaching activities of general physics experiment course, teachers need to combine with actual teaching requirements, set the appropriate thinking questions, check the experiment operation conditions of students through thinking. In the experiment process, students think the topic through collaboration in the class, elaborate the final discussion outcome to teachers, and thus form interaction between teachers and students. Application of peer instruction in the teaching of general physics experiment course can be regarded as an innovation. On one hand, it can stimulate students' interest in learning, get them actively involved, and help them have a more in-depth and comprehensive understanding of physics; on the other hand, teachers can organize teaching ideas and flexibly adjust teaching plans while students are thinking. In the fierce discussions of students, teachers may offer them appropriate guidance and corrections, and listen to their discussion contents. 
Under normal circumstances, their opinions may be contrary to the experimental result, teachers should guide students how to think correctly and carry out experiments correctly. By collecting and organizing the feedback from students, teachers can carry out targeted teaching activities and improve the teaching syllabus[3].

\section{Application of Peer Instruction in the Teaching of General Physics Experiment Course}

Analyzing the Application of Peer Instruction in the Teaching of General Physics Experiment

Course. Before implementing the teaching activities of general physics experiment course, teachers need to design questions according to actual requirements, which shall not only arouse students to think but also allow them to complete tasks within the prescribed time. Therefore, the designed questions shall facilitate students to conduct in-depth discussion and involve in memory judgments, data computing and other complex questions as much as possible.

The teaching contents of the general physics experiment course should be designed according to actual teaching needs. For example, in the measurement of sound speed, teachers can design the following questions. (1) Why the measurement of sound speed can be achieved by virtue of the ultrasonic wave spreading in the air? (2) How to form an ellipse by using the phase comparison method? (3) With the increase in the space between receiving terminal and transmitting terminal of voltage ceramic transducer, why does the signal amplitude get smaller and smaller? Every two groups think about one question. According to the survey, almost no student can answer these questions before the experiment, yet only $22 \%$ of students can answer them through discussions. However, there are greater limitations in answers, having some errors with correct answers. According to statistics of student answers after the experiment in the second cycle, $28 \%$ of students can answer before the experiment, and $86 \%$ of students can answer through discussions. Although the answers are more appropriate compared with the first time, but they still fail to reflect the nature of questions. After the test, $98 \%$ of students can give the standard answer through discussion, and these students can understand the true meaning of the answer[4]. Therefore, this cycled experiment can continuously improve the cognitive level of students, the effects of the second time are significantly better than the first time, and the third time is better than the second time. When the final round ends, students can give the most correct answer, and they can share and exchange with others combined with experimental experience. For example, through self-inquiry thinking, students are able to find that the refractive indexes of different sound media vary, which can be measured by adopting the opaque media. This idea is mainly benefited from the analysis and explanation of last group on measurement of sound speed, which is also a full play given to the peer instruction. In the subsequent teaching process of experiment course, teachers are primarily responsible for answering and guiding the questions and puzzles proposed by students in experiment, reminding students to beware of precautions during the experiment and ensuring the accuracy of the experimental results. At last, teachers should guide students to discuss and exchange for clearing puzzles. On one hand, application of peer instruction in general physics experiment can stimulate students' interest in learning, get them actively involved, and arouse their interest in physics experiment; on the other hand, teachers can greatly reduce the intensity of teaching, so that they have more time to participate in the students, listen to students' ideas, guide and correct the students' deviations, and enhance students' learning efficiency.

For the teaching of physics experiment course not using peer instruction, students show low enthusiasm in physics experiment, do not have flexible abilities, and fail to efficiently cope with unexpected problems despite the same nature of such problems; meanwhile, these students do not throw themselves into physics experiment and seriously lose interests in carrying out the experiment teaching activities. According to the data survey, after objectively analyzing the application of peer instruction in physics experiment course, more than $85 \%$ of students have significantly increased interests in physics experiment teaching, and the cognitive level of experiment teaching is improved correspondingly; $95 \%$ of students think that application of peer instruction in physics experiment has 
a very intuitive effect, which can help students concentrate on learning and stimulate interests in learning. In addition, after many experiments, students shift their perspectives and attitudes of looking at things, they become more flexible and more bold to think, dare to closely communicate and exchange with others, and draw final correct conclusions[5].

Strategies for Application of Peer Instruction in the Teaching of General Physics Experiment Course. Peer instruction is a common teaching method of current physics experiment course. It mainly caters to the requirements of new curriculum educational reform, changes the dominant position of teachers in the traditional classroom, and highlights the dominant position of students. It mainly aims to stimulate students' interest in learning, self-inquiry spirit and innovative spirits, help students to form good study habits and physical literacy, and facilitate them to comprehensively develop their overall quality. However, in the implementation of experiment teaching activities, teachers guide the communication and exchange between students, which can inspire their associative thinking abilities. Collision of thinking will inevitably produce more creative sparks, so students dare to doubt and analyze the divergent views. Conceptual conflicts can greatly stimulate students' curiosity and thirst for knowledge, motivate them to look up relevant information to seek solutions to problems more actively, facilitate to develop good learning ability, and play a positive role in the improvement of students' experimental and practical abilities.

Update the Theoretical Basis. With the development of current education cause, new curriculum educational reform advocate students to develop overall qualities comprehensively and have self-learning ability. As the guider and organizer of classroom teaching, teachers should clarify this educational goal, cultivate self-learning ability of students in a targeted and planned way, constantly innovate and improve the teaching concepts, keep pace with the times, and thus ensure that the teaching activities may cater to the needs of times. Although the educational concepts of new curriculum standards are constantly deepened and popularized, they remain in the minds of teachers owing to influences of traditional examination-oriented education. Such teaching concepts will lead to low efficiency of teaching. Therefore, currently the traditional cramming teaching method should be transformed into heuristic and discussion-based teaching, which establishes interesting teaching activities, stimulate students' interest in learning, and mobilize their enthusiasm to participate in, so that students can not only enhance their theoretical knowledge base, but also develop good study habits and improve the learning ability.

In physics experiment teaching, teachers should combine with diversified teaching concepts and integrate situated teaching concepts with cooperative teaching concepts. First of all, situated teaching concept means to share information with cooperation partners in order to enhance the teaching effects, strengthen the sense of substitution and create the cultural environment. Secondly, peer instruction and cooperative teaching concept have common in knowledge sharing through interaction and exchanges between teachers and students, yet the latter abandons the one-way communication of traditional knowledge flowing from teachers to students, and attaches more importance to multi-way communication of knowledge between students along with between teachers and students; Teachers play an intermediary role, emphasizing the combination of actual teaching contents to set classroom thinking questions. In contrast, the cooperative teaching concept focuses on setting cooperation links to solve the problem. Both of their purpose is to emphasize that students solve new issues by combining with their learned knowledge, deepen students' cognitive level of new knowledge, and play an exemplary role. Therefore, it is essential to strengthen the innovation of theoretical basis of peer instruction. By integrating with advantages of other teaching theories, it helps to further give play to peer instruction.

Scientifically Plan the Course Teaching Process. Application of peer instruction in physics experiment teaching can add the exchange links between teachers and students and between students. When designing the teaching contents, teachers should pay attention to teaching arrangements in each link, ensure to fully control the time arrangement of each stage in practical application, shorten the time for explaining secondary contents, and distribute more time in key points. In addition, teachers should establish more diversified preview methods, the preview links may be completed by virtue of 
network platform, such as completing the teaching content preview through QQ platform and YY education platform and sending the preview knowledge points to the designated QQ group file sharing, so that students can download from the network server terminal; students will send the completed title to the designated teachers' mailbox, teachers organize and analyze the completion conditions of students, and design the teaching contents and process in a targeted manner on this basis.

In addition, as one of the indispensable part of peer instruction, peer discussions need to consume lots of time. Therefore, teachers should combine with the consumed time of other teaching links for reasonable arrangements, ensure the discussion time can meet the needs of students' question analysis, and summarizes the insights and conclusions after peer discussions. The final summary part is particularly important as well, which is the conclusion of the whole class. It can correct wrong answers of students, make a fair evaluation on efforts made by students for experiment teaching activities, and give play to the guiding role of teachers in the class.

\section{Conclusions}

In conclusion, application of peer instruction in general physics experiment course plays a very prominent role, has positive effects on students' physics literacy and cultivation of study habits, help deepen students' interests in learning physics experiment, master richer subject knowledge, and subtly cultivate students' capabilities of identifying problems, analyzing problems and solving problems, so that they dare to express their opinions and views in public, and it has a far-reaching impact on the development of students' creativity and logical thinking ability. In addition, it should be noted that since peer instruction has little practical application experience, students may contradict with it, so it is necessary to fully combine with students' individual learning characteristics, continuously popularize and promote peer instruction, give better play to peer instruction, and enhance the teaching effects of general physics experiment course

\section{Acknowledgements}

This work is supported by the Educational Commission of Hubei University for Nationalities (Grant No. 2013JYZ04)

\section{References}

[1] Craig D. Cox,Michael J. Peeters,Brad L. Stanford,Charles F. Seifert. Pilot of peer assessment within experiential teaching and learning[J]. Currents in Pharmacy Teaching and Learning,2013,54:.

[2] Dianne Ramm,Anna Thomson,Andrew Jackson. Learning clinical skills in the simulation suite: the lived experiences of student nurses involved in peer teaching and peer assessment[J]. Nurse Education Today,2015,356:.

[3] Shri Ramaswamy,Ilene Harris,Ulrike Tschirner. Student Peer Teaching: An Innovative Approach to Instruction in Science and Engineering Education[J]. Journal of Science Education and Technology,2015,102:.

[4] Youdas James W,Hoffarth Brianna L,Kohlwey Scott R,Kramer Christine M,Petro Jaime L. Peer teaching among physical therapy students during human gross anatomy: perceptions of peer teachers and students.[J]. Anatomical Sciences Education,2013, 15:.

[5] Ten Cate Olle,Durning Steven. Peer teaching in medical education: twelve reasons to move from theory to practice.[J]. Medical Teacher,2012,296:. 